\title{
Социальные проблемы
}

\section{В ЭКОНОМИКе}

УДК 331.101:103

\section{Теоретико-методические аспекты анализа трудовых ресурсов предприятия}

\author{
(C) 2013 г. О.Г. Арасланова
}

Устойчивый экономический рост любого предприятия зависит в первую очередь от эффективного использования труда работников и улучшения качества трудовых ресурсов.

На сегодняшний день существует достаточно большое количество различных трактовок определения трудовых ресурсов. Термин «трудовые ресурсы» впервые применил академик С.Г. Струмилин в 20-е годы XX столетия. Им трудовые ресурсы определяются как часть населения страны, которая по физическому развитию, приобретенному образованию, профессионально-квалификационному уровню способна заниматься общественно полезной деятельностью.

А.Я. Кибанов под трудовыми ресурсами понимает категорию населения, занимающую промежуточное положение между экономическими категориями «население» и «совокупная рабочая сила». По его мнению, в количественном отношении в состав трудовых ресурсов входит все трудоспособное население, занятое независимо от возраста в сферах общественного хозяйства и индивидуальной трудовой деятельности. Сюда включаются также лица трудоспособного возраста, потенциально способные к участию в труде, но занятые в домашнем и личном крестьянском хозяйстве, на учебе с отрывом от производства, на военной службе [1].

А.Л. Мазин обращает внимание на то, что величина трудовых ресурсов зависит от следующих обстоятельств: официально установленных возрастных границ - верхнего и нижнего уровней трудоспособного возраста, доли трудоспособных среди населения трудоспособного возраста, а также численности участвующих в общественном труде из лиц за пределами трудоспособного возраста [2].

На наш взгляд, под трудовыми ресурсами можно понимать совокупность трудоспособных членов общества, включая как уже вовлеченных в процесс производства, так и остающихся за его рамками, но способными стать при определенных условиях работниками [3, с. 50].

Трудовые ресурсы выступают на двух уровнях: на уровне национальной экономики (в масштабе народ-

\footnotetext{
* Канд. пед. наук, доц., зав. каф. экономики Вятского государственного гуманитарного университета (ВятГГУ).
}

ного хозяйства конкретно взятой страны) и на глобальном уровне (в масштабе мирового хозяйства в целом).

Трудовые ресурсы организации (предприятия) в этом случае можно определить по следующей формуле:

$$
\mathrm{УTП}_{п}=\mathrm{P}_{\text {п }}+\mathrm{KP}_{\text {попп }} \text {, }
$$

где УТП приятия или организации; $\mathrm{P}_{\text {п }}$ - работники предприятия или организации; КРЗ ${ }_{\text {попп }}$ - кадровый резерв предприятия или организации из состава подрастающих поколений.

К трудовым ресурсам на национальном или глобальном уровне применима следующая формула:

$$
\mathrm{TP}_{\mathrm{Hг}}=\mathrm{P}_{\mathrm{cHг}}+\mathrm{TH}_{\text {нов }} \text {, }
$$

где $\mathrm{TP}_{\text {нг }}$ - трудовые ресурсы в национальном или глобальном масштабе; $\mathrm{P}_{\text {снг }}$ - рабочая сила в национальном или глобальном масштабе; $\mathrm{TH}_{\text {нов }}$ трудоспособное население, не занятое в общественном воспроизводстве.

По мнению Л.А. Костина, к основным понятиям процесса управления трудовыми ресурсами можно отнести объект и субъект управления, предмет управления и механизм управления трудовыми ресурсами. Как объект управления трудовые ресурсы выступают одновременно производителями и потребителями материальных и духовных благ, ВВП. Субъектом управления на макроуровне выступает государство, на мезоуровне - регион, а на микроуровне - отдельные предприятия [4]. Предметом управления трудовыми ресурсами в целом является система социально-экономических отношений, которые складываются по поводу управления процессами воспроизводства рабочей силы.

На наш взгляд, управление трудовыми ресурсами - это часть системы управления как экономикой страны в целом, так и отдельного региона или предприятия. Оно направлено, во-первых, на удовлетворение потребностей всех субъектов управления в квалифицированной рабочей силе, во-вторых, на обеспечение занятости трудоспособного населения и его оптимального распределения, в-третьих, на эффективное использование трудовых ресурсов, в-четвертых, на создание системы социальных 
гарантий для работников. Эти цели являются взаимосвязанными и должны реализовываться на уровне каждого субъекта управления трудовыми ресурсами.

Механизм управления трудовыми ресурсами представляет собой совокупность отношений, форм и методов воздействия на их формирование, распределение (перераспределение) и использование [5, с. 13]

По мнению Г.В. Савицкой [6, с. 130], при рассмотрении вопроса обеспеченности отдельно взятого предприятия трудовыми ресурсами необходимо отметить, что от эффективности их использования зависят объем и своевременность выполнения всех работ, степень использования оборудования, машин, механизмов и как следствие - объем производства продукции, ее себестоимость, прибыль и ряд других экономических показателей.

Обеспеченность предприятия трудовыми ресурсами определяется путем сравнения фактического количества работников по категориям и профессиям с плановой потребностью. Особое внимание уделяется анализу обеспеченности предприятия кадрами наиболее важных профессий. Необходимо также анализировать качественный состав персонала по уровню квалификации. Квалификационный уровень работников во многом зависит от их возраста, стажа работы, образования и т. д. Поэтому в процессе анализа изучают изменения в составе рабочих по этим признакам.

Поскольку изменения качественного состава персонала происходят в результате его движения, для характеристики движения рабочей силы рассчитывают и анализируют следующие показатели:

Коэффициент оборота по приему персонала $\left(\mathrm{K}_{\text {пр }}\right)$

$$
\mathrm{K}_{\text {пр }}=\frac{\text { Количество принятого на работу персонала }}{\text { Среднесписочная численность персонала }}
$$

Коэффициент оборота по выбытию $\left(\mathrm{K}_{\mathrm{B}}\right)$

$$
\mathrm{K}_{\mathrm{в}}=\frac{\text { Количество уволившихся работников }}{\text { Среднесписочная численность персонала }}
$$

$$
\text { Коэффициент текучести кадров }\left(\mathrm{K}_{\text {тк }}\right)
$$

Количество уволившихся работников по собственному желанию

$$
\mathrm{K}_{\text {тк }}=\frac{\text { и за нарушение дисциплины }}{\text { Среднесписочная численность персонала }}
$$

Коэффициент постоянства состава персонала предприятия $\left(\mathrm{K}_{\text {пс }}\right)$

Количество работников,

$\mathrm{K}_{\text {пс }}=\frac{\text { проработавших весь год }}{\text { Среднесписочная численность }}$
Необходимо изучить причины увольнения работников (по собственному желанию, сокращение кадров, нарушение трудовой дисциплины и др.).

Напряженность в обеспечении предприятия трудовыми ресурсами может быть несколько снята за счет более полного использования имеющейся рабочей силы, роста производительности труда работников, интенсификации производства, комплексной механизации и автоматизации производственных процессов, внедрения новой, более производительной техники, усовершенствования технологии и организации производства. В процессе анализа должны быть выявлены резервы сокращения потребности в трудовых ресурсах в результате проведения перечисленных мероприятий.

Если предприятие расширяет свою деятельность, увеличивает свои производственные мощности, создает новые рабочие места, то следует определить дополнительную потребность в трудовых ресурсах по категориям и профессиям, а также источники их привлечения [6, с. 133].

Резерв увеличения выпуска продукции за счет создания дополнительных рабочих мест определяется умножением их прироста на фактическую среднегодовую выработку одного рабочего в отчетном периоде:

$$
\mathrm{P} \uparrow \mathrm{B} \Pi=\mathrm{P} \uparrow \mathrm{KP} \cdot \Gamma \mathrm{B}_{1},
$$

где Р $\uparrow$ ВП - резерв увеличения выпуска продукции; $\mathrm{P} \uparrow \mathrm{KP}$ - резерв увеличения количества рабочих мест; ГВ $\mathrm{B}_{1}$ - фактическая среднегодовая выработка рабочего.

Полноту использования персоналом рабочего времени можно оценить по количеству отработанных дней и часов одним работником за анализируемый период времени, а также по степени использования фонда рабочего времени (ФРВ). Такой анализ проводится по каждой категории работников, по каждому производственному подразделению и в целом по предприятию.

ФРВ зависит от численности рабочих, количества отработанных дней одним рабочим в среднем за год и средней продолжительности рабочего дня.

Для оценки уровня интенсивности использования персонала применяется система обобщающих, частных и вспомогательных показателей производительности труда. К числу обобщающих показателей относятся среднегодовая, среднедневная и среднечасовая выработка продукции одним работником, а также среднегодовая выработка продукции на одного работника в стоимостном выражении. Для характеристики частных показателей рассматривают затраты времени на производство единицы продукции определенного вида (трудоемкость продукции) или выпуск продукции определенного вида в натуральном выражении за один человеко-день или человеко-час. При рассмотрении вспомогательных показателей необходимо проанализировать затраты времени на выполнение единицы определенного вида работ или объем выполненных работ за единицу времени. 
Наиболее обобщающим показателем производительности труда является среднегодовая выработка продукции одним работником (ГВ зависит не только от выработки рабочих, но и от удельного веса последних в общей численности персонала $\left(\mathrm{У}_{\text {д }}\right)$, а также от количества отработанных ими дней (Д) и продолжительности рабочего дня (ЧВ). Среднегодовую выработку продукции одним работником можно представить в виде следующих факторов:

$$
\text { ГВ }
$$

Аналогичным образом можно анализировать изменение среднегодовой выработки рабочего (ГВ ), которая зависит от количества отработанных дней одним рабочим за год, средней продолжительности рабочего дня и среднечасовой выработки:

$$
\Gamma^{\prime}=\text { Д } \cdot \text { П } \cdot \text { ЧВ. }
$$

Изменение уровня среднечасовой выработки за счет определенного фактора можно рассчитать по следующей формуле:

$$
\Delta \mathrm{YB}_{X_{i}}=\frac{\Delta \Phi \mathrm{PB}_{X_{i}}}{100-\Delta \Phi \mathrm{PB}_{X_{i}}} \cdot \mathrm{ЧB}_{0},
$$

где $\Delta \Phi \mathrm{PB}_{X_{i}}$ - относительное сокращение фонда рабочего времени за счет проведения определенного мероприятия, \%.

Резервы увеличения среднечасовой выработки определятся следующим образом:

$$
\begin{aligned}
& \mathrm{P} \uparrow \mathrm{ЧB}=\mathrm{ЧB}_{\mathrm{B}}-\mathrm{ЧB}_{1}= \\
& =\frac{\mathrm{B}_{1}+\mathrm{P} \uparrow \mathrm{B} \Pi}{\Phi \mathrm{PB}_{1}-\mathrm{P} \downarrow \Phi P B+\Phi \mathrm{PB}_{\text {д }}}-\frac{\mathrm{B}_{1}}{\Phi \mathrm{PB}_{1}},
\end{aligned}
$$

где Р ЧВ - резерв увеличения среднечасовой выработки; ЧВ можный и фактический уровень среднечасовой выработки; Р个ВП - резерв увеличения объема выпуска продукции за счет внедрения мероприятий НТП; ФРВ ${ }_{1}$ - фактические затраты рабочего времени на выпуск продукции отчетного периода; $\mathrm{P} \downarrow$ ФРВ - резерв сокращения рабочего времени за счет механизации и автоматизации производственных процессов, улучшения организации труда, повышения уровня квалификации работников и др.; ФРВ ростом выпуска продукции, которые определяются по каждому источнику резервов увеличения производства продукции с учетом дополнительного объема работ, необходимых для освоения этого резерва, и норм выработки.

Резерв прироста среднечасовой выработки за счет проведения определенного мероприятия можно рассчитать и по следующей формуле:

$$
\mathrm{P} \uparrow \mathrm{ЧB}_{X_{i}}=\frac{\mathrm{P} \downarrow \Phi \mathrm{PB}_{X_{i}}}{100-\mathrm{P} \downarrow \Phi \mathrm{PB}_{X_{i}}} \cdot \mathrm{ЧB}_{1}
$$

где $\mathrm{P} \downarrow \Phi \mathrm{PB}_{x_{i}}$ - процент относительного сокращения фонда рабочего времени за счет проведения определенного мероприятия, \%.

Кроме того, большое значение для оценки эффективности использования трудовых ресурсов на предприятии в условиях рыночной экономики имеет показатель рентабельности персонала (отношение прибыли к среднесписочной численности ППП):

$$
R_{\text {ППп }}=\frac{\begin{array}{c}
\text { Прибыль от реализации } \\
\text { продукции и услуг (П) }
\end{array}}{\text { Среднесписочная численность (ППП) }} \cdot 100 \cdot
$$

Факторную модель данного показателя можно представить следующим образом:

$$
R_{\Pi п \Pi}=\frac{\Pi}{\Pi \Pi \Pi}=\frac{\Pi}{\mathrm{B}} \cdot \frac{\mathrm{B}}{\mathrm{B} \Pi} \cdot \frac{\mathrm{B}}{\Pi \Pi \Pi}=R_{\text {об }} \cdot Д_{\mathrm{P \Pi}} Ч Г \mathrm{~B},
$$

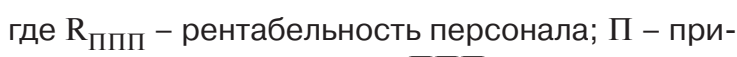
быльотреализациипродукции; ППП-среднесписочная численность промышленно-производственного персонала; В - выручка от реализации продукции; ВП - стоимость выпуска продукции в текущих ценах; $\mathrm{R}_{\text {об }}$ - рентабельность оборота (продаж); Д реализованной продукции в общем объеме ее выпуска; ГВ - среднегодовая выработка продукции одним работником в текущих ценах.

По мнению Л.А. Адамайтис [7, с. 14], в процессе анализа необходимо оценивать, насколько эффективно используются трудовые ресурсы, а также насколько рационально формируется и используется фонд оплаты труда.

Анализ трудовых ресурсов и оплаты труда можно проводить по следующим основным этапам:

I этап - анализ обеспеченности и движения трудовых ресурсов (коэффициент оборота по приему, коэффициент оборота по выбытию, коэффициент текучести кадров, коэффициент постоянства кадров и др.).

II этап - анализ интенсивности и эффективности использования трудовых ресурсов (интенсивности - анализ использования фонда рабочего времени; эффективности - анализ годовой выработки и трудоемкости, факторный анализ производительности труда и трудоемкости).

III этап - анализ формирования и использования фонда оплаты труда (анализ состава и структуры фонда оплаты труда, абсолютное и относительное изменение фонда оплаты труда, соотношение темпов роста производительности труда и его оплаты).

К оценке показателей движения и эффективности использования трудовых ресурсов можно сделать следующие комментарии (табл. 1, 2). 


\section{Социальные проблемы в экономике}

\begin{tabular}{|c|c|c|c|c|}
\hline \multirow{2}{*}{\multicolumn{5}{|c|}{ Комментарии к I этапу анализа }} \\
\hline & & & & \\
\hline $\begin{array}{l}\text { Коэффициент } \\
\text { оборота } \\
\text { по приему }\end{array}$ & $\begin{array}{l}\text { Коэффициент } \\
\text { оборота } \\
\text { по выбытию }\end{array}$ & $\begin{array}{l}\text { Коэффициент } \\
\text { текучести }\end{array}$ & $\begin{array}{c}\text { Дополнительные } \\
\text { условия }\end{array}$ & Характеристика \\
\hline Рост & Рост & Рост & $k_{\text {пр }} \triangleright k_{\text {выб }}$ & $\begin{array}{l}\text { Негативная ситуация - свидетельствует об отрицательном клима- } \\
\text { те, сложившемся на предприятии, или недостаточном материаль- } \\
\text { ном и моральном стимулировании, однако обеспеченность работни- } \\
\text { ками возрастает. }\end{array}$ \\
\hline Рост & Рост & Рост & $k_{\text {пр }} \triangleleft k_{\text {выб }}$ & $\begin{array}{l}\text { Крайне негативная ситуация - свидетельствует об отрицательном } \\
\text { климате, сложившемся на предприятии, или недостаточном матери- } \\
\text { альном и моральном стимулировании, сопряжена с недостаточно- } \\
\text { стью трудовых ресурсов на предприятии. }\end{array}$ \\
\hline Рост & Снижение & Снижение & - & $\begin{array}{l}\text { Положительная ситуация - свидетельствует о повышении обеспе- } \\
\text { ченности предприятия трудовыми ресурсами, об улучшении клима- } \\
\text { та в коллективе. }\end{array}$ \\
\hline Снижение & Рост & Снижение & - & $\begin{array}{l}\text { Неоднозначная ситуация - с одной стороны, может свидетель- } \\
\text { ствовать о повышении обеспеченности предприятия трудовыми } \\
\text { ресурсами, с другой стороны, если наблюдается увеличение финан- } \\
\text { совых результатов, то может свидетельствовать об оптимизации } \\
\text { численности работников предприятия. }\end{array}$ \\
\hline Снижение & Рост & Рост & - & $\begin{array}{l}\text { Крайне отрицательная ситуация - увеличивается число выбыв- } \\
\text { ших работников на предприятии, что приводит к снижению обеспе- } \\
\text { ченности трудовыми ресурсами. }\end{array}$ \\
\hline Снижение & Снижение & Снижение & - & $\begin{array}{l}\text { В целом положительная ситуация - свидетельствует о стабилиза- } \\
\text { ции кадрового состава на предприятии. }\end{array}$ \\
\hline
\end{tabular}

$k_{\text {выб }}$ - коэффициент оборота по выбытию.

Таблица 2

\begin{tabular}{|c|c|c|c|}
\hline $\begin{array}{c}\text { Производительность } \\
\text { труда }\end{array}$ & Трудоемкость & $\begin{array}{c}\text { Выручка } \\
\text { от продаж }\end{array}$ & $\begin{array}{c}\text { Численность } \\
\text { работников }\end{array}$ \\
\hline Рост & Снижение & Рост & Рост \\
\hline Рост & Снижение & Снижение & Снижение \\
\hline Рост & Снижение & Рост & Снижение \\
\hline Снижение & Рост & Снижение & Снижение \\
\hline Снижение & Рост & Рост & Рост \\
\hline
\end{tabular}

Помимо сравнения показателей в динамике, рекомендуется проводить сравнение со среднеотраслевыми показателями [7, с. 16].

На третьем этапе проводится анализ эффективности использования фонда оплаты труда. Для этого в первую очередь необходимо оценить его динамику и структуру, в том числе: абсолютное изменение фонда оплаты труда в целом и по отдельным видам выплат, а также изменение удельного веса различного рода выплат, провести сравнительный анализ темпов роста производительности труда и средней оплаты труда. В случае если темпы роста оплаты труда превышают темпы роста его производительности, ситуацию следует признать отрицательной, поскольку она приводит к относительному перерасходу фонда оплаты труда. В заключение анализа рекомендуется провести расчет этого относительного отклонения, который позволит количественно измерить сумму относительной экономии (перерасхода) фонда оплаты труда с учетом изменений масштабов деятельности организации - объемов производства и продаж:

\section{этапу анализа}

Однозначно позитивная ситуация - свидетельствует, что на фоне расширения масштабов деятельности повышается эффективность использования трудовых ресурсов.

Негативная ситуация - свидетельствует об отрицательном климате и о формальном повышении эффективности использования трудовых ресурсов (за счет того, что темпы снижения численности выше темпов снижения выручки).

Положительная ситуация - свидетельствует об оптимизации численности работников на предприятии.

Безусловно отрицательная ситуация - на фоне развития кризиса снижается заинтересованность работников в результатах работы, эффективность труда снижается.

В целом отрицательная ситуация - свидетельствует о нерациональном увеличении численности, темпы роста численности работников превышают темпы роста выручки от продаж.

$$
\Delta \text { ФОТ }_{\text {отн }}=\text { ФOT }_{1}-\text { ФOT }_{0} \cdot \mathrm{TP}_{N}
$$

$\Delta$ ФОТ $_{\text {отн }}>0$ - относительный перерасход ФОТ;

$\Delta$ ФОТ $_{\text {отн }}<0$ - относительная экономия ФОТ.

По результатам проведенного анализа рекомендуется провести ряд мероприятий управленческого характера [5, с. 16 - 17].

В ходе анализа следует обратить внимание на причины выбытия работников за нарушение трудовой дисциплины. В этом случае можно предложить следующие варианты действий:

1) усиление контроля за трудовой дисциплиной;

2) повышение квалификации работников, сопровождающееся ростом производительности труда;

3) при снижении производительности труда и в случаях, когда производительность труда значительно ниже среднеотраслевых показателей, следует: оценить оснащенность рабочего места необходимым оборудованием; проверить соответствие установленного оборудования современным требованиям; оценить, как осуществлялось снабжение материальными 
ресурсами, не было ли перебоев в снабжении. Если наблюдаются простои, вызванные недостаточным использованием оборудования, то необходимо оценить возможность его замены на более новое и современное. Если же простои вызваны плохим снабжением материальными ресурсами, то следует проводить мероприятия по повышению качества снабжения;

4) наряду с вышеуказанными действиями проводят оценку фонда рабочего времени, выявляя его потери.

Такой анализ можно проводить по каждой категории работников, по каждому производственному подразделению и в целом по предприятию. Среди основных причин могут быть дополнительные отпуска с разрешения администрации, невыходы на работу по болезни, прогулы.

В данном случае действия администрации направляются на снижение потерь. Можно рекомендовать мероприятия, направленные на укрепление здоровья работников: оплата медицинских осмотров, профилактических мероприятий (прививки и т. д.). Помимо этого, возможна оплата абонементов на посещение работниками спортивных залов, проведение различных соревнований внутри предприятия и т. п.

В случае если работник остается не заинтересованным в результатах работы, то менеджеру по кадрам необходимо провести беседу о причинах такого отношения к труду, а также рассмотреть вопрос перевода работника на другое место;

5) по результатам анализа фонда оплаты труда прежде всего должны приниматься управленческие решения в части контроля над нужным соотношением темпов роста производительности труда $\left(\mathrm{TP}_{\text {пт }}\right)$ и его оплаты (ТР $\left.{ }_{\text {от }}\right)$.

В случае если ТР пени (в зависимости от методики расчета $\Delta$ ФОТ отн, а также соотношения постоянной и переменной части ФОТ) имеет место относительный перерасход ФОТ, т. е. «проедание» доходов оказывается больше, чем их прирост. Длительное сохранение такой ситуации имеет крайне негативные последствия вплоть до банкротства организации. При отсутствии возможности существенного повышения доходов (или тем более - прогнозируемом их снижении) необходимы достаточно жесткие управленческие решения, несмотря на их непопулярность. Это может быть сокращение численности определенных категорий работников и расширение круга обязанностей оставшегося персонала, снижение оплаты труда работников (в первую очередь за счет экономии на премиальных и иных аналогичных выплатах).

Если имела место относительная экономия ФОТ, значит, рост масштабов деятельности и получаемых при этом доходов, соответственно и рост производительности труда были относительно выше, чем рост оплаты труда $\left(\mathrm{TP}_{\text {пт }}>\mathrm{TP}_{\text {от }}\right)$. При этом оплата труда могла и не возрастать или ее рост не соответствовал результатам ведения бизнеса. С позиции менеджмента ситуация может быть оценена положи- тельно, так как любой руководитель стремится к экономии затрат, в т. ч. в части оплаты труда (при этом, кстати, сокращается и размер начисляемых на ФОТ очень значительных страховых взносов и взносов от несчастных случаев).

Однако следует иметь в виду и отрицательные последствия сохранения в течение длительного время большого разрыва между $\mathrm{TP}_{\text {пт }}$ и $\mathrm{TP}_{\text {от }}$. Это может привести к потере со стороны персонала материальных стимулов к труду и дальнейшему росту бизнеса, текучести материально и морально неудовлетворенных сотрудников и т. п.

Обосновав некоторые рациональные пропорции между $\mathrm{TP}_{\text {пт }}$ и $\mathrm{TP}_{\text {от, }}$ руководству следует в большей степени привязать доходы работников к расширению бизнеса и росту его доходности. Возможно, следует разработать новую систему оплаты труда, при которой работник более заинтересован в результатах своего труда и деятельности компании в целом. Желательно периодическое, пусть и не столь значительное, но повышение заработной платы, в т. ч. за счет выплат стимулирующего характера. К числу моральных стимулов можно отнести поощрение работников за успехи в работе грамотами и именными подарками.

Данные исследования методического характера могут быть полезны представителям ученой общественности для анализа существующих проблем, касающихся трудовых ресурсов, а также руководителям организаций, предприятий, специалистам для совершенствования организации труда на основе гибкого сочетания интересов работников и работодателей.

\section{Библиографический список}

1. Экономика и социология труда: Учебник / под ред. А.Я. Кибанова - М.: ИНФРА-М, 2009. - 584 с.

2. Мазин А.Л. Экономика труда: уч. пос. для студентов вузов. - М.: ЮНИТИ-ДАНА, 2008. - 575 с.

3. Арасланова О.Г. Теоретико-методологические основы экономических отношений по вопросам труда, воспроизводства и применения рабочей силы современного общества // Наука и экономика. 2012. № 1(9). С. $48-54$.

4. Управление трудовыми ресурсами. Справочное пособие / под ред. Л.А. Костина. - М.: Экономика, 1987. - 235 с.

5. Арасланова О.Г. Система управления трудовыми ресурсами региона // Научный потенциал. 2012. № 1 (8). С. 12 - 16.

6. Савицкая Г.В. Анализ хозяйственной деятельности предприятия: Учеб. - 3-е изд., перераб., и доп. М.: ИНФРА-М, 2006. -425 с.

7. Адамайтис Л.А. Анализ трудовых ресурсов, оплата труда и обоснование управленческих решений. Материалы Всероссийской заочной научнопрактической конференции 8 ноября 2010. Проблемы и перспективы социально-экономического развития регионов / под ред. А.В. Зоновой. - Киров: Изд-во ВятГГУ, 2010. - 247 с. 